\title{
Chapter 2 \\ The Consumption and Production of Fisheries Information in the Digital Age
}

\author{
Janet Webster and Eleanor Uhlinger
}

\subsection{The Fisheries Information Life Cycle}

Fisheries scientists persistently create, communicate, and use information. In fact, if they did not, there would be no fisheries science. To exist, science must be part of a continuum where shared information, from casual hallway communications to rigorously reviewed articles, documents the questions asked and the solutions suggested. Relevant information is critical to the success of basic and applied fisheries research projects. Identifying the relevant at the beginning of a project and then communicating what is important out of the project are elements of the life cycle of fisheries information. Both have become simultaneously easier and more difficult as the amount of information increases within the digital environment. The access to information is simpler and yet more nuanced.

As producers and consumers, we sustain the life cycle of fisheries information. We learn to consume information as students, often modeling our behavior from our professors. They give us a stack of reprints to read, and those articles become the foundation for our exploration into fisheries sciences. Or, we start with a pivotal article and work back through its references and forward through its sphere of influence defined by citations. Now, new alerting tools and search engines broaden our information horizons, enriching our perspectives while obscuring the relevant through the deluge. Consumption can be a feast of delectable facts, theories, datasets and findings or an orgy of the same leaving indigestion rather then satisfaction.

This changing information environment also affects scientists as producers of information. We are faced with a plethora of publishing options where once there were only a few selective journals. We can publish in highly specialized titles with limited audiences, target the mainstream with high impact journals, issue findings electronically through blogs or web sites, or present at conferences where all becomes part of a streaming video record. The decisions we make when

J. Webster $(\bowtie)$

Oregon State University Libraries, Hatfield Marine Science Center, 2030 Marine

Science Drive, Newport, OR 97365, USA

B.A. Megrey, E. Moksness (eds.), Computers in Fisheries Research, 2nd ed., 
producing information are no longer straightforward, but require thought and preparation so the information produced is consumable and not half-baked or forgotten on a back shelf.

The information life cycle has not changed fundamentally with the advent of computers, the Internet and digital resources. However, the environmental factors affecting how we produce and consume information have changed. A major factor is the growth of the digital network and how that shapes the ways information is published, disseminated and accessed. We should consider other factors as well when thinking about how to effectively consume and produce information. Fisheries science is no longer just about natural science; we need to increase our awareness of the information from the social sciences as the problems we address often have significant human components to them. The scale we work within has expanded as long term datasets become available, as genetic work reveals finer granularity, and as geographic limits diminish with extended global networks. The breadth of sources widens and we look to non-scientists for assistance with local information and insight. All these factors shape how we use information in our work. All enrich, yet none make it easier as they demand more decisions throughout the scientific process.

The following attempts to assist with that decision making by describing approaches, options and challenges to consuming relevant information and then producing, or communicating, the same. On the consumption side, we will discuss how to identify, obtain and manage fisheries information. As tools change, the focus will be on strategies with specific examples of current tools. On the production end, we will explain the decisions to be made regarding intended audiences and possible outlets, publishing options, copyright considerations, access points, and archiving responsibilities. Finally, we will return to the electronic information environment to put the consumption strategies and publishing decisions into a larger context. Here we will touch on the economics of publishing and access, possible legal issues, the concept of the digital library, and information integrity and preservation.

\subsection{Consuming Information}

\subsubsection{Identifying Fisheries Information}

There is a Chinese proverb that states: "Void of a long-term plan will bring you trouble soon." This proves applicable to that point when you are starting a project. You need to consider your question and then your strategy for finding the answer. Uncovering the pertinent literature is a critical strategic step. Starting by typing keywords into Google ${ }^{\mathrm{TM}}$ returns reams of information, but often with a degree of randomness that may leave a queasy feeling of missing the right pieces. 
Before starting to look for information, it is useful to carefully think about what types of information you are looking for, who may produce it, and where it might appear. Then, you can tackle how to find it. Here are examples of questions to consider at this step in your research strategy.

- Broad or narrow topic?

The level of specificity may indicate where to start and where to look for information. The bigger or less focused the question, typically the more broadly you will need to look to identify as much relevant information as possible. It is difficult to answer a broad fisheries question such as the effect of global warming on salmon populations, by only referring to the work of population dynamics researchers.

- Limited geographic scope or global?

If the problem is highly localized, you will want to concentrate on local information, yet with an eye on how others may have addressed the same problem. If global, the sources will be multinational and perhaps multi-lingual.

- Applied or basic research?

The research continuum from basic to applied is paralleled by an information continuum. As research moves towards the more applied, different sources of information become more useful such as trade publications, patents, and government documents.

- Science or policy?

Many fisheries questions have policy implications. So, it is smart to be aware of information that may be outside the normal scientific communication channels.

- Who?

Understanding who has worked on the question provides a starting point as does considering who may have funded research or be interested in the outcome. Organizations as well as individuals may have a vested interest in the issue.

- Where?

Related to the Who question is where the topic may be discussed. This suggests not only which journals may contain articles, but also which conferences or electronic discussion forums may address the topic. Considering where the conversation is generated may provide insight into where to look for current information as well as possible audiences for future communication.

\subsubsection{The Tools}

Another proverb suggests that "a long march starts from the very first step." That step after considering the types of information is identifying what tools may be helpful. These range from the general to the very specialized, from classic to contemporary, and from free to very expensive. All have a place in the information gathering process, but some will prove easier to use, more relevant, 
or more accessible depending on your circumstances and need. Tools change over time; some may become obsolete while new ones are developed. In the following, some specific tools are described with a discussion of their strengths and weaknesses in terms of content and access. They are grouped to help you identify the types of tools and then which ones you may be able to access given individual circumstances.

\subsubsection{General Science Indexes}

These broad, science indexes generally cover the core fisheries literature adequately. They are solid starting points as you will find the major fisheries journals as well those in related fields such as ecology, biology and zoology. They are not the complete universe of fisheries literature, though. Additionally, almost all of those described are accessible through paid subscriptions only. Pricing usually depends on the size of the institution (e.g. number of FTEs) and size of the database (e.g. number of years covered).

\section{Web of Science ${ }^{\circledR}$}

Formerly known as the ISI Science Citation Index, the current electronic iteration continues to provide access to a broad suite of science journals in multiple disciplines. (A master journal list is available from the Thomson Scientific web site - www.thomsonscientific.com.) First published in the early 1960 s, its continuing strength is its capacity to relate articles through citations allowing a user to investigate who is citing whom, who is working on related topics, and what are a topic's core papers. Other resources such as CiteSeer, Google Scholar ${ }^{\mathrm{TM}}$ and Scopus ${ }^{\mathrm{TM}}$ are beginning to track citation patterns but currently not with the same accuracy (Roth 2005; Jacsó 2006a). Its greatest weakness is the lack of coverage of monographs, conference proceedings, and report literature. It is also one of the most expensive general science databases so access may be very limited unless your institution subscribes. Subscriptions to Web of Science ${ }^{\circledR}$ are priced in part by number of 5 year blocks of records; access to a complete range of years covered by the index increases the cost. While powerful, the search interface is not clean using some jargon that for occasional users makes searching challenging. The display of results can be cryptic until familiarity is gained with use. Web of Science ${ }^{\circledR}$ remains the deepest general science index in chronological coverage and consistency of sources indexed. Its sister index, Web of Social Science ${ }^{\circledR}$, shares the same interface and is similar in construction and purpose. It is useful for delving in to the social and economics sides of fisheries.

\section{Biosis}

The tomes of Biological Abstracts are now electronically accessible as Biosis. This classic index for biological information covers over 6,500 journals 
including the core fisheries titles. Coverage includes some conference proceedings and report. Its strength is its longevity (in print since 1927 with electronic access from the 1970s) and the depth of the indexing making it very searchable by subject and keyword for the power user. Its weakness is the lack of consistent coverage of non-mainstream publications including foreign language material and trade titles. Access is through subscription and is expensive. It can be purchased through a variety of vendors who then offer access to it through their search interface.

\section{Scopus $^{\mathrm{TM}}$}

Scopus $^{\mathrm{TM}}$ is Elsevier Publishing's foray into the general scientific index arena complete with citation tracking. It covers more publications than Thomson's Web of Science ${ }^{\circledR}$, but may do it less consistently with noticeable gaps in coverage (Jacsó 2006c). The types of publications covered are broad including journal articles, conference proceedings, patents, books and trade journals. The journal literature makes up its core. The depth of coverage in temporal terms varies depending on the subject area; life and health sciences coverage extends back to 1966 while the social sciences are covered from 1996 forward. For fisheries, the major journals are covered but not all the book series or potentially useful trade publications. The search interface is straight forward and the results display versatile and readable. Scopus ${ }^{\mathrm{TM}}$ is competition to Web of Science ${ }^{\circledR}$, yet remains an expensive alternative resource.

\subsubsection{Specialized Indexes}

Fisheries scientists are fortunate to have subject-specific indexes providing deeper access to the published literature than the more general ones. Often starting broadly and then working to the specific is recommended as you may find material that is tangentially related in the broad searching and then can hone in on the very specific. The down side of this approach is the duplication you will encounter. The following two examples are primarily accessible through paid subscriptions. While not as expensive as the general science indexes, these still represent a sizable investment for an organization.

\section{Aquatic Science and Fisheries Abstracts (ASFA)}

In the late 1950s, fisheries scientists at the Food and Agriculture Organization of the United Nations (FAO) began compiling a bibliography of documents "which contribute to knowledge of living resources of the seas and inland waters" (Food and Agriculture Organization of the U.N. 1958) The goal was, and remains, to provide coverage of the world literature through an international cooperative effort of monitoring and entering relevant documents. This effort is administered by the ASFA Secretariat located within the FAO Fisheries Department who then partners with Cambridge Scientific Abstracts 
(CSA), a commercial publisher, to enhance and produce the database. The current database contains over one million citations from the early 1970s to the present; older ones are added selectively.

Coverage ranges from the mainstream science journals to conference proceedings to national documents. Over 50 partners including international organizations (e.g. International Council for the Exploration of the Seas and Network of Aquaculture Centres of Asia-Pacific) and national institutions (e.g. CSIRO Marine Research and IFREMER) contribute to the database making it rich in content. The official list of partners is maintained by on the ASFA Secretariat web site (ASFA Secretariat 2006). The geographic diversity and variety of research foci of the contributing partners are strengths of $A S F A$. For some, this diversity is distracting as there is considerable non-English material as well as citations to documents difficult to access (e.g. limited distribution). The traditional subject scope was on living resources and a more applied perspective. That has broadened as more ecological journals are now monitored. ASFA is inconsistent in its coverage of the social science side of fisheries and living resources; management documents are not always included due to the reliance on local partners to contribute what they deem important. CSA does not regularly include material from social science and development journals, instead adding more science citations.

$A S F A$ consists of five subsets:

- Biological Sciences and Living Resources;

- Ocean Technology, Policy and Non-Living Resources;

- Aquatic Pollution and Environmental Quality;

- Aquaculture Abstracts;

- Marine Biotechnology Abstracts.

To many users, these subsets are transparent. To database vendors, the subsets are useful as they can be packaged separately or multiple configurations depending on the audience. CSA packages the complete $A S F A$ and allows users to select subsets to search. National Information Services Corporation (NISC), another database publisher, packages the Biological Sciences and Living Resources subset with other databases to create its popular product, Aquatic Biology, Aquaculture \& Fisheries Resources. Most institutions subscribe to the online version of the database through CSA or NISC for a significant annual fee. Those who contribute to the database as a partner receive free access through the internet or by CD available from the ASFA Secretariat. Institutions in low income food deficit countries are also eligible for free access. $A S F A$ remains an excellent specialized index for fisheries scientists.

Fish and Fisheries Worldwide

National Information Services Corporation (NISC) created this citation database by combining various existing databases, some ongoing and some ceased. These include: 
- FISHLIT (from the J.L.B. Smith Institute of Ichthyology)

- U.S. Fish and Wildlife Reference Service database

- A fish subset of MedLine

- South Africa's Fishing Industry Research Institute Database

- Castell's Nutrition References

- NOAA's Aquaculture database

This approach retains the value of older databases that are no longer maintained and enhances them with the addition of new material from other sources. Too often, older indexes become inaccessible as nobody sees the value of transforming them from a stand-alone database or a print bibliography. NISC attempts to capture such historic citation caches and build with them. Fish and Fisheries Worldwide is smaller than ASFA (less than 600,000), but very useful for its coverage of taxonomic records, sub-tropical freshwater fish, and U.S. local and federal government material. It also tends to cover some geographic areas more thoroughly than $A S F A$, Africa in particular. It is focused on fish and fisheries rather than the aquatic environment making it a useful tool for fisheries scientists. It is not as expensive as CSA's $A S F A$ making it attractive to institutions not needing the breadth of the full $A S F A$ and looking for more specificity in some areas. Its interface is simple and quite intuitive for all levels of users.

\subsubsection{The Worldwide Web as an Index}

The rapid growth of digital information builds the wealth of information available through web search engines. The Web still is a morass of information, good, bad and ugly. The search engines such as Google ${ }^{\mathrm{TM}}, Y$ ahoo $^{\circledast}$ and $A s k^{\mathrm{TM}}$ are useful tools for sorting through the vast amount of digital information. As these engines evolve, their differences become more apparent and users should expect to see more differentiation in how they search and display results. Scientists need know what sources they are searching. The established indexes such as Biosis and ASFA clearly explain what journals and sources they draw from; the web search engines are rarely as clear, and never as focused. However, they tend to cast a broad net, useful for establishing the scope of a project or trying to find something specific fast or with little effort.

Whatever the reason for using a web search engine, it is how many start and end the quest for information. It has obvious and not so obvious problems, yet can yield satisfactory results. Fisheries scientists should recognize the limitations of web searches and know when to use indexes that will go deeper into the literature. This entails checking the "about" on each search engines home page. Rarely does a company specify exactly how they are searching and ranking the results of the search. However, a user can get an idea and recognize why different engines come up with different results. Google ${ }^{\mathrm{TM}}$ was the first, and holds the patent, on the search and ranking system referred to as page-ranking (Page et al. 1998). The algorithm considers how many pages are linking to the specific page as well as relative importance of the referring page. Ask ${ }^{\mathrm{TM}}$ tweaks the page-ranking by 
attempting to cluster like pages and analyses the relationship among those pages, thus returning pages that link within a topic area and not those random linkages. Some, such as $Y a h o{ }^{\circledR}$, integrate paid or sponsored sites into the rankings; while this practice probably does not affect search results for fisheries science information, it could for fisheries trade information. In contrast, searches within the indexes described earlier are worked through a closed set of citations with field tags (e.g. author, keyword, title) so results are ranked by matches to the contents of the fields searched and not by the complexities of relative importance among the citations. It is a controlled information environment as compared to the wide open Web.

Yet, the convenience of a simple interface and direct links to the full text of articles make web search engines attractive. The rest of the information world database vendors and libraries included - scrambles to package their resources with as simple an interface. They are also tailoring what is searched and how to provide the scholarly audience search tools that integrate with existing work patterns and computer desktops. Scirus from Elsevier, Google Scholar ${ }^{\mathrm{TM}}$ and Windows Live Academic are examples of free multidisciplinary indexing and abstracting databases.

\section{Google Scholar ${ }^{\mathrm{TM}}$ (http://scholar.google.com/)}

Google $e^{\mathrm{TM}}$ launched this service in 2004 with much fanfare. In essence, it is a subset of the Web providing access to "peer-reviewed papers, theses, books, abstracts and articles, from academic publishers, professional societies, preprint repositories, universities and other scholarly organizations" (Google 2005). Yet, it does not specify which publishers and institutions participate leaving the user to guess or take it on faith that the coverage is broad and wide (Jacsó 2005a). For example, Elsevier Publishing does not participate leaving out a major portion of peer-reviewed articles. Additionally, it is unclear how often and how deep various sites are mined for results leaving gaps in coverage revealed if the publisher's site is searched directly (Jacsó 2005a). Research conducted on its coverage and utility suggest that it is stronger in the sciences that social sciences and has a definite English language bias (Neuhaus et al. 2006). The search interface is familiar and simple with an advanced option that increases its utility. The links to full text articles (if the user's institution has implemented the service) make searching and getting items more efficient. With the addition of citations to the search results, some suggest that Google Scholar ${ }^{\mathrm{TM}}$ can replace Web of Science ${ }^{\circledR}$ or the newer, Scopus (Pauly and Stergiou 2005) while others urge scholars to use it in addition to the more structured databases (Bauer and Bakkalbasi 2005). The fisheries scientist will find it an easy place to start, but should continue exploring the literature in one of the specialized indexes for more thorough coverage of the field's varied information. 
Chapter 2 October 3, 2008 Time: 21:18 Proof 1

Scirus (http://www.scirus.com/)

Elsevier Publishing started this free search service focused on its deep database of articles and over time has added other sources such as patent data and electronic theses and dissertations (Pruvost et al. 2003). Unlike Google Scholar ${ }^{\mathrm{TM}}$, Scirus is open about what is covered within its scope providing direct links to those partners. The search interface includes the familiar simple box as well as an advanced option that helps the user narrow results by terms, years, format and source. The strength for fisheries people is the coverage of Elsevier's journals, some of the most widely cited in the field. Its weakness is the hype as Elsevier claims that it is "the world's most comprehensive science-specific index" (Elsevier Ltd. 2004). Again, Scirus is more structured than Google Scholar ${ }^{\mathrm{TM}}$ and more transparent giving it greater credibility. It is a decent resource as long as it is used in conjunction with others.

Windows Live Academic (http://academic.live.com/)

This Microsoft product (in beta testing in 2006) offers a simple search of a broad suite of journals and conferences. By listing the participating publishers and their products, a user can decide if this free product would be useful. The search interface is simple to the point of frustration. The display of results is clean yet often misses links to abstracts and the relevancy ranking is not clear. Also, there is much duplication of records. For the fisheries scientists, it will reveal much of the mainstream literature though not in a very usable or malleable manner (Jacsó 2006b). Microsoft's interest in creating a useful information tool indicates sensitivity to how researchers work and a desire to be part of the process of the information seeking process.

\subsubsection{Searching Effectively}

The myriad of tools available to the fisheries scientists adds confusion to identifying information. The tools described above represent some of the most accessible or most useful. In deciding which to use, what you are investigating can suggest were to look. Broad, inter-disciplinary questions need to be investigated using indexes that are temporally and topically deep while geographically inclusive and covering multiple disciplines. One tool is not adequate for a thorough search for information. Each has its particular strengths in terms of coverage and search sophistication. Any sophisticated searcher should be aware of the scope of content of the database or span of coverage of a web search service. Also, the user will eventually know when to go deeper for information and when the obvious is good enough.

Another consideration in choosing an index or a search engine is the search interface and the results display. Features are constantly being refined by all; however, there are basic ones that make a tool usable (e.g. searching within a 
field such as title) and those that increase its value (e.g. linking to full text). Some users will always execute simple searches and not experience some of the satisfaction that results from refining a search or ferreting out a resource not readily searchable by keyword. The following discusses three functions inherent in search interfaces that can reveal differences which may influence use.

\subsubsection{Searching Options}

The ubiquitous search box presents the simple option of entering in a single keyword and getting results. To some, a complex search is adding more keywords. Any database or search engine should have this basic search option as there are times that a single term or a simple phrase is adequate, and more choices confusing or extraneous. However, there are times that a simple keyword search does not produce any results or does not reveal the relevant. One obvious possibility is misspelling; not all databases have a spell checking facility. Other possibilities to consider are the structure and the scope of the resource being searched, and the structure of the search query.

Scope has been discussed earlier; however, it is useful to briefly discuss it again along with structure. The various indexes will return different results from the same search strategy. The differences reflect their scope and content. Different web search engines return varying results as they use slightly different searching algorithms and relevancy factoring (Spink and Cole 2006). Tools exist to visualize the overlap (and lack of it) between various search engines (Jacsó 2005b). An efficient approach to the overlap issue is the ability to search across resources. Some web search engines use this approach (e.g. Dogpile). Within the citation databases, some vendors allow you to search multiple databases simultaneously, so you expand what you are searching and usually increase your results (although you also increase the duplicated citations.) Librarians are developing federated search tools so the user can generate a simple query that is executed across a wide suite of information resources (Avrahami et al. 2006). This concept is quite powerful as web search engines do not penetrate the "Deep Web", material protected by passwords, licenses or structure. An example of the later are library catalogues that while openly searchable are not mined by the typical web search engine as their records are within a database that is not probed by the web crawlers. The same premise holds true for a structured database such as Biosis or the Web of Science ${ }^{\circledR}$. Basic searches using Google $e^{\mathrm{TM}}$ will return many results, but will not necessarily search deeply into specialized indexes or resources.

The structure of the search query is another consideration for effective searching. A simple keyword search can build into a query with multiple field-specific terms. Adding synonyms or related terms can increase search results as can searching across all fields in the resources. For example, if the basic search in a given system is limited to selected fields such as title and author, it will not return citations where the keyword is embedded in the abstract. Building effective search queries involve the above as well as informed 


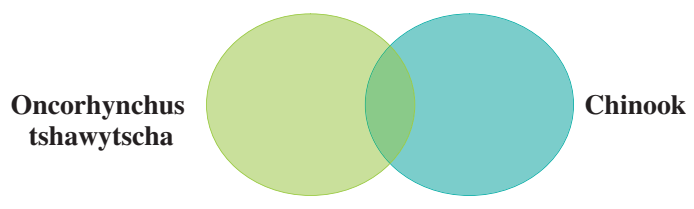

Fig. 2.1 Simple Boolean search indicating the possibilities of expansion (considering both sets so references with either term), and narrowing (considering references containing both terms)

use of phrasing and the Boolean terms ("and", "or" and "not"). Some web search engines assume multiple keywords have "and" between each rather than "or"; this approach tends to restrict results. If adjacency of keywords is important, such as "population dynamics" or "freshwater aquaculture", using quotes is usually a trigger for a search engine to search for the phrase rather than the individual words. Boolean terms allow users to build sets, narrowing or expanding results, and helping them find the most relevant information. An obvious time that a fisheries scientist would use Boolean terms is searching a particular species where it is important to use the scientific and common names to retrieve all pertinent references (Fig. 2.1).

Some search interfaces build in Boolean searching into their advanced options using multiple boxes with connecting terms (Fig. 2.2). The option is almost always available even if query and connecting terms must be manually entered.

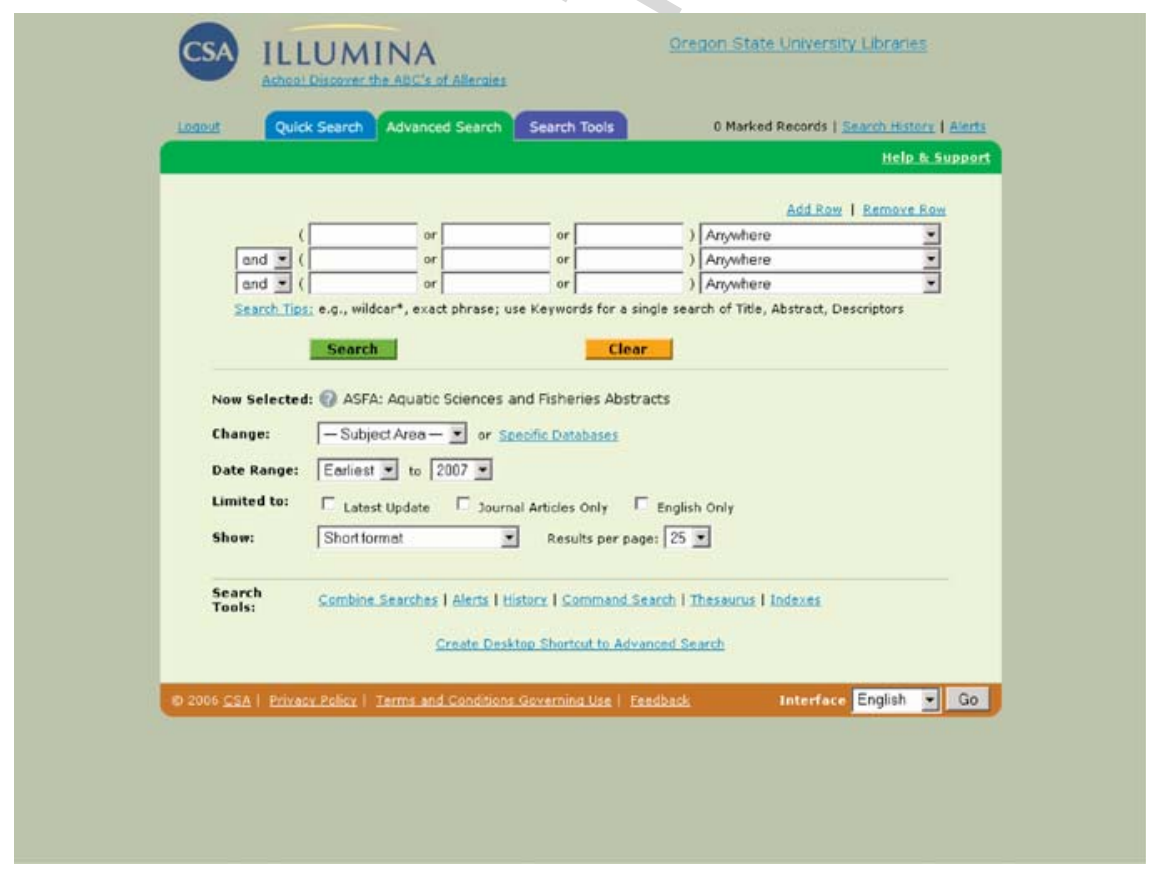

Fig. 2.2 Cambridge Scientific Abstracts' Illumina search interface integrates Boolean search terms 
Fig. 2.3 Boolean search illustrating the variety of combinations possible with thoughtful searching of terms $(*$ is a common sign for truncation and in this example will retrieve results containing the root of salmon such as salmonids)

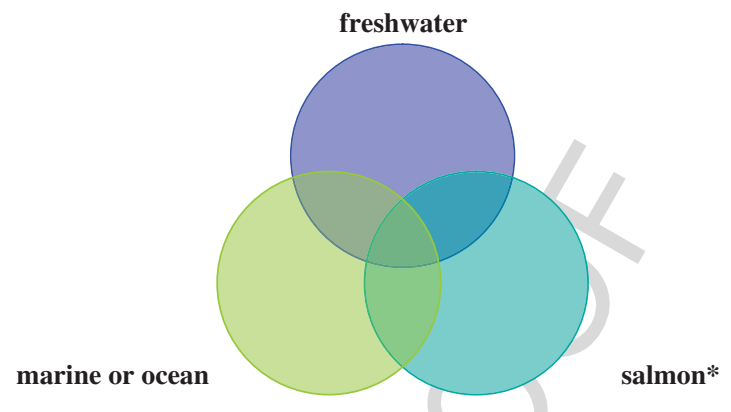

Figure 2.3 illustrates how Boolean terms work conceptually when combining search terms. Using a basic search, each concept is placed in quotes or parenthesis and searched to form a set of results. These sets are then combined with "and" to narrow the search to a subset. Using "or" as the combing terms would expand the results to include all sets. The term, "not", is used to exclude a concept that interferes with the results; for example, to find information on the marine phase of salmonids, the sets of keywords or phrases are searched and then the freshwater set excluded.

A basic search option is very powerful if used thoughtfully. However, a well designed advanced search option is critical as it allows for more specific and often more efficient searching. Few besides those who search daily and librarians regularly use advanced features; in fact most who use web search engines rarely exploit the great potential of more advanced searches (Jansen et al. 2000). Databases and web search engines of value offer advanced search features. Some of the features are described below:

- Field searching

- Example: if you only want to retrieve documents written by a particular author and not those containing citations to that author, you would limit your search to the author field.

- Example: if you are looking for articles that have a primary focus on a topic, you may limit a keyword search to the title rather than the entire record including the abstract.

- Limiting

- Example: if you want only the most recent references, you limit your search to the current year within the publication date field.

- Example: if you only want articles from a certain journal, you specify that journal in the source field hence limiting the range of publications searched.

- Example: if you want to find all articles published by authors in three countries, you add those countries within the author affiliation field to your search. 


\section{- Format}

- Example: you only want those references that are readily available as full text, so you limit your search to full text.

- Example: you want a review article, so use the publication type field to refine your search.

- Example: you may want to find images so will want to limit your search by file extension such as jpeg or gif.

- Thesaurus or keyword list

- Example: you are looking for a scientific name but cannot remember exactly how to spell it.

- Example: you are not finding anything using a particular keyword, so want to find other synonyms.

- Search history

- Example: you executed a complex search for a species that you want to combine with an earlier search on habitat and life history.

- Example: after a long search session, you want to retrieve an earlier search that had some references you forgot to note.

Search interfaces constantly evolve as their creators integrate user feedback into making a better mousetrap. While laudable, it is also disconcerting as you get used to working in certain ways. Too many bells and whistles become distracting without adding much utility. So, when deciding on tools to use, it is perfectly acceptable to use those that present the most understandable and easy for you to use interface. Mastering the basic search using Boolean logic will greatly improve search results. Adding an understanding of field limiting and using controlled vocabulary will enhance efficiency and efficacy.

\subsubsection{Displaying Results}

The display of results can affect their utility to the searcher. Too much information slows down the ability to scan for relevancy, yet too little leads to guessing and perhaps missing important documents. A well designed interface allows the user to tailor, to some degree, the results display showing more or less detail as desired. For instance, a simple list of titles can be easily scanned for interesting citations; yet, a more complete record with the abstract is valuable if looking for something particular. Web search engines do not currently have the same capacity for manipulating the display of results. A decent interface will also allow the user to sort the results by date or relevancy if not other factors. Again, web search engines do not currently allow this as they are not working with a controlled and limited database of citations.

There are certain obvious elements of any display of results. These include the following: 
- Title of the resource

- Author(s) including first initials if not complete name

- Basic citation information such as the journal title, volume, date and pages or conference name

- Abstract or simple description

The last element in the list, the abstract, is often critical in deciding whether some thing is useful. Many citation databases have complete abstracts as written by the authors or database editors while web search engine automatically create a summary using various strategies. The content of the summary should help the user decide if the resource will be useful meaning relevant to the current search. Fisheries scientists are accustomed to the classic abstract so can read through a well-written one and grasp the research question, the methodology and the results. Web summaries can be problematic as they do not have a consistent structure and being short, do not always provide enough context or information (White et al. 2003). On the positive side, it is often simple to click through to the document itself or a more complete description of the item.

Additional display features, while not critical, can be useful. These are usually of two types: the first group being elements that provide more information about the item and the other type being connections to additional information or the item itself. The former are most visible in citation databases with structured records. The value of the records is increased with the addition of more complete publication information including publisher information and a complete citation as well as more information on the author such as affiliation and contact information. Often subject headings or descriptors have been assigned; these allow you to search for other records with the same descriptors, a useful tactic when exploring a topic.

The later type of elements, external linkages, is a newer development as linkages to full text of articles and other resources have evolved. With web search engine results, the greatest feature is the link to the full text of an item, although too often that link is to an incomplete citation or reference buried within another document. Linking to full text is not assured as the full text of an article may be restricted to those with licenses or authority. The citation databases can be integrated with an institution's journal databases so linkages are automatic if the institution has a subscription to that journal. This is done through implementation of an OpenURL resolver, a software that gathers the information about a user, the institution's licenses and the information resources, and then matches the access rights (McDonald and Van de Velde 2004). Even with the limitations to access, linking out to full text resources is a boon to the fisheries scientists providing faster access to information. Another form of link is to related records or similar pages which can lead to resources of interest. Sometimes these linked resources are related only through payment to the search engines, and sometimes they are related through shared keywords or source. Within a scientific information database, the relatedness may be through shared references or shared subject descriptors. 
The results display in many citation databases give the user more complete information about a resource and allow some manipulation of the results set. The results display of web search engines can reveal a wealth of information not covered by the citation databases and usually provide some kind of direct access to the full text if available. So, the differences in display once again reinforce that one tool does not satisfy every information need or every user's expectations.

\subsubsection{Using Results}

Finally, there are differences in how to use the results. Linkages to more information including the full text exemplify one use. Others involve manipulating the results for further use. Effective use of results can ease the research process. Tracking what has been searched and found relevant allows compilation of sources in a logical manner. The web search engines are not as conducive to this more structured information search; rather than marking a list of references and then checking as a batch, you must click back and forth between the results page and possible documents of interest. When using a web search engine, one strategy is to maintain a research log and cut and paste relevant or interesting web page addresses along with the date accessed so you can return to the site. The citation databases allow the user to mark references of interest as they are perused, compiling them into a subset. Then the user can print, download, email or simply review the subset.

\subsubsection{Managing Information}

Another Chinese proverb states "Once on a tiger's back, it is hard to alight." Ferreting out the information can become addictive and the consumer of information becomes consumed with the task. Knowing when to stop searching and start reading and synthesizing is as critical as knowing how to start searching. It is almost impossible in this age of rapid information transfer and burgeoning information resources to feel that you have found everything on a topic. However, you can be confident if you have worked through your information searching logically and systematically. The logic can be temporal - starting with the historic pieces and working forward or vice versa. Or, it can be database-centric executing similar searches across multiple databases. Over time, you will devise your own methods and process.

Maintaining a research log can be useful for managing the process. This entails simply noting what databases you have searched when and what search strategies you used. You can then re-execute those strategies at a later date if working on a long term project. You will also remember what you have already done if you get interrupted or return to a project.

Another important component of managing the process and the information gathered involves organizing what you find. Random citations jotted down on 
slips of paper or emailed to your mailbox are easily lost and have little context. It is not enough to copy or print off various articles; you need to keep them organized so you can use them. One method is the old-fashioned list compiled as information is gathered with the corresponding reprint file. This method has been updated with the advent of easy-to-use bibliographic software such as EndNote ${ }^{\top M}$. One way of looking at this type of software is that it replaces the old card files; however, it has much more potential as a highly useful research tool (Mattison 2005; Webster 2003). Most bibliographic software allows the user to enter records with the typical fields of author, title, source, add personal annotations through keywords, notes and abstracts, and even link to digital versions of the item. The resulting personal citation database is searchable and serves as a tool to manage your research. Beyond that, the most valuable aspects of bibliographic software are its ability to import records you have identified while searching the citation databases and its capacity to format those citations in a variety of styles as you use them in your writing. Some see this as just another software package to learn, so procrastinate. Those that do make the effort to use one of the many available bibliographic software packages available find it a valuable tool for managing information from consumption through production.

\subsubsection{Obtaining Information}

It is one thing to identify information resources and yet another to actually get them to read and review. This step is made easier with the increase in digital information and the integration of links to that from the citation databases and within the Web. Those of us working within research, governmental and educational institutions often enjoy broad access to digital information as well as well-stocked libraries of print material. Obtaining material is not always perceived as an issue. However, we enjoy that access because the digital material is either freely available through open access repositories or web sites, or purchased by the institution. The institutional entity usually responsible for maintaining adequate access to information is the library. Remove the licenses the library has negotiated, purchased and maintained, and a fisheries scientist would be frustrated by the lack of seamless access to electronic journals in particular. So, the library should be a researcher's first means of obtaining information whether virtually or physically. A core principle of librarianship is to connect the user with the information needed (Ranganathan 1963). The format, topic or source does not matter, but access does. If stymied in obtaining information, work with your librarian to secure electronic access or to facilitate a loan or purchase.

Not all fisheries scientists have a librarian or a library. Exploring if the material is freely available in electronic format is currently the favored approach. This entails looking beyond an initial search of the Web to investigating the 
digital holdings of relevant organizations. For example, the Food and Agriculture Organization of the U.N. has a large digital document repository that is available to all; however, most web searches will not penetrate this rich source of full text documents as it is not structured to be readily mined by the search engines (Food and Agriculture Organization of the U.N. 2006) One strategy for finding electronic documents is to look to the organization responsible for publishing the document in question or funding the research. The growing trend towards institutional repositories that capture the digital output of an organization increases access. However, often these repositories must be searched individually by going to the institution's web site.

If a freely available digital version of a piece of information is not readily available, the next step is to request it from the author or producing organization. This used to be a common practice and why authors continue to get a stack of reprints from their publishers (although often at a cost.) More authors are advocating for electronic reprints usually as a pdf that can be posted on an institutional web site for sharing with colleagues. Before posting to a site that is publicly available, the authors should verify that they secured that right as part of the copyright agreement with the publisher. If this is not the case, another way of sharing electronic reprints with requestors is to put it on an FTP site that is either password protected or time limited so access is restricted to those authorized.

The final option is paying for the information, something libraries do daily, but the individual researcher does rarely. Many publishers of scientific articles and reports have simplified paying for individual articles. There will be times when reviewing citations that you will link to an article that your institution does not subscribe to, or you have linked to that article in a way that the publisher does not recognize that you are affiliated with a subscribing institution. At that point, most systems will request a login and password, or your credit card number. Before despairing, check with your librarian to see if you should have access. If not, then you will have to decide if the article is worth the cost.

\subsubsection{Staying Current with Information}

Given the perceived deluge of information, it can be daunting to stay current with research, policy changes and management decisions. Various tools are available to help address the challenge. These include electronic tables of contents, personalized alerts, discussion lists and RSS feeds. Each has its strengths and weaknesses, but all provide ways to stay informed.

Browsing the tables of contents of relevant journals is a tried and true method. It is an easy way to see what is being published as well as a means of discovering information that you may overlook in a search. Most publishers maintain journal web pages containing the tables of contents by issue. These are easily browsed when accessed. A more effective method is to subscribe to email 
alerts either through the publisher or through a compiler. Setting up alerts involves going to the publisher's web site, registering and selecting those journals which interest you. Then, you will receive an email whenever a new issue is published. You will need to go to a variety of publisher sites to cover all of the publications you may want. An alternative if available to you is to use a service such as Current Contents $^{\mathrm{TM}}$ or ingenta ${ }^{\mathrm{TM}}$ that allow you to set up an account and select journals by a variety of publishers. The strength of such services is the ability to manage one account for access to multiple publishers and their journals. The drawback is the cost; both the examples above involve a substantial annual subscription fee that your institution may or may not choose to pay.

In addition to table of contents alerts, many publishers and citation databases include a feature for search alerts. The concept is that you may have a search that you want to conduct regularly such as a species, an author, or citations to your own publications; a search alert provides a mechanism for running these search strategies on a regular basis and having any results emailed to you. Even if a favorite citation database or publisher does not have the alert capability, it may have a way to store your search strategies so you can easily retrieve them and run at a later date. This alleviates reconstructing a search that was productive. Some alerts are automatically run and sent weekly even if there are no new items; others only generate an alert when there is something to send. Either way, it is a simple way to keep informed on new publications by certain authors or on a particular topic.

Another way to stay informed is to subscribe to relevant electronic discussion lists. Some generate too much traffic in your email box, but others may be a valuable resource for learning about new developments in your field. Lists seem to be a particularly useful for announcements of new books and reports as publishers or authors find them a useful way to generate interest in a publication. LISTSERV $^{\circledR}$, one of the major software tools used for creating discussion lists, maintains a searchable list of those lists thus providing one tool for identifying appropriate discussion lists (http://www.lsoft.com/lists/listref.html). Asking colleagues which lists they subscribe to is often the most effective way of finding relevant lists. Most professional organizations also maintain email lists that can be useful ways to stay informed.

RSS (real simple syndication or rich site summary) feeds are one more tool to mention in this day and age. Many web sites incorporate this tool as a means to "push" new information to those interested. A typical way that such feeds are encountered is at the bottom of many web sites where a stream of news is constantly changing; this is an RSS feed. Subscribing to RSS feeds allows you to monitor changes in a web site of interest such as a blog on marine fisheries management or a particular site that lists fisheries jobs. A simple way to do so is by using an aggregator such as Bloglines or NetVibes. A web service that allows subscribers to set up a personalized web site that monitors selected web sites and blogs. 
Chapter 2 October 3, 2008 Time: 21:19 Proof 1

\subsubsection{Information Consumed}

Searching effectively entails all of these steps.

- Learning how to structure searches

- Investigating options for displaying and using results

- Selecting the most appropriate resource to search.

The last may be the most important. The best search interface is meaningless if the suite of information being searched is irrelevant to the searcher. The broadest citation database is worthless if it does not cover the discipline being investigated. The World Wide Web is multi-dimensional and searching its most accessible dimension is not adequate for scientific research. So, select your information tool carefully and search intelligently. As the Web, information resources and computing evolve, more tools will become available for consuming information.

\subsection{Producing Information}

After completing the analysis of research findings, the penultimate step of the scientific process is communicating the results. Scientists present their findings to others for ratification, verification, discussion, consequently contributing to a discipline's body of literature. After building upon the work of others by "consuming" information, we scientists produce information. At this step, you make decisions that can help shape the body of scientific literature through effective scholarly communication.

\subsubsection{Audience}

Various modes of communication are available to scientists and choosing the proper one begins with determining the intended audience for the work. The intended audience often shapes the focus of the content, the style and the venue. For example, the elements necessary to explain a scientific finding are different than those for recommending changes to fisheries policy; one may require more text while another may depend heavily on data presented in graphical format. Traditionally, fisheries scientists wrote for other scientists. In contemporary society, they also may need to communicate to the lay person, policy makers or students. Each audience responds best to communication directed to their information needs and use patterns (e.g. regular reading of scientific journals versus browsing of fisheries web pages). With the advent of electronic delivery, it is easy to lose sight of intention. Scientists may read research summaries on public websites rather than seek out the peer-reviewed paper. Or, students may stumble on the paper when a summary or simpler explanation may better fit their needs. This blurring is driven by practical considerations of time and effort 
(it is fast and relatively simple to find information on the Web versus sorting through the peer-reviewed journals even when available electronically). Yet, it does not negate considering audience when producing information. The blurring suggests that information once produced for a single audience of scientists can now be used by more than audience; so, thoughtful production is necessary.

Scientists write technically for other scientists, and tend to follow a prescribed structure that reflects the scientific method. The outlets are scientific journals and conference proceedings with the peer-reviewed journal article being the most credited communication piece. While individual journals have different styles and requirements for authors, all require common elements such as an introduction, an explanation of materials and methods, and a discussion and analysis of data and results. Additionally, fisheries scientists use common terminology such as internationally accepted scientific binomial names for the organisms described, international units of measurement, and technical abbreviations and acronyms that are often used without explanation. These standards facilitate the communication among scientists as readers can maneuver through the common structure.

By contrast, communicating fisheries science to general audiences requires less technical language that describes the subject matter in an understandable manner as these readers do not share the common language of peer-reviewed science. Illustrations become an essential means of explaining the issues and the process for addressing them. Organisms may be referred to by their local vernacular or common names rather than their binomial scientific names. This common practice makes literature more accessible to local readers and those unfamiliar with scientific names. The methodology may be the focus of the writing rather than the findings (e.g. explaining how a pit tag works) if that addresses the interest of the audience. The purpose is usually more education and information rather than the drive to document and validate found in peer-reviewed communication.

Policy communications blend the popular and the scientific. When fisheries scientists work with policy makers, they are usually providing an expert opinion or scientific findings. Policy makers are not scientists although many may have extensive scientific experience and credentials. Consequently, scientific language is adapted so concepts and findings are well articulated and understandable to the lay person. Fisheries scientists when working with policy makers decide what role they are playing - scientist or advocate - and shape their writing to reflect the decision (Lackey 2006). Some would say that this decision is arbitrary, yet the communication will be shaped by the nature of the language, the tone and the viewpoint. This makes policy communication challenging.

\subsubsection{Publishing Venues}

Once the audience is recognized, you select a publishing venue that addresses your audience, its needs and its information seeking behavior. The growth of 
the Web adds new venues as well as expands the reach of existing ones. The borders between venues blur. Peer-reviewed articles are available electronically so become elements of websites rather than limited to a bound journal. Policy statements are posted to web sites in a timely manner so edits and revised drafts are immediately open to scrutiny by the interested public and those affected by the decision. The electronic environment opens communications in terms of access and timeliness. While venues blur, fisheries scientists still need to focus on a primary one when crafting their communication. The publishing venue is shaped by those who contribute to it, those who read what is published and then by the venue itself.

\subsubsection{Peer-Reviewed Journals}

Scientists prefer peer-reviewed journals for most scholarly scientific publications as their primary audience reads them and the authors usually get greater credit for their career. Peer-review is a collaborative process whereby papers are submitted to an Editor who in turn solicits anonymous review of the work by other scientists working in the field. These anonymous reviewers assure quality control by evaluating the materials and methods; the veracity and repeatability of the findings; and the contribution, if any, that the new work makes to the field. Peer-reviewed journals can be broad in scope (Science and Nature) or more specialized (Fisheries Oceanography). They may be produced by commercial publishers (Elsevier, Wiley), societies (American Fisheries Society, World Aquaculture Society), institutions (Journal of the Marine Biological Association of the $U K$ ), or governments/non-government organizations (National Research Council of Canada, the International Whaling Commission).

The cost of peer-reviewed journals is highly variable, with commercial publications often being extremely expensive and government publications being less expensive or even free. This is an important point to consider when selecting a publishing outlet; a high cost journal may have a more limited readership than a freely available publication. Again, the intended audience is one consideration in selecting the appropriate publishing venue.

Scientists debate the quality and "impact" of peer reviewed scientific journals. "Impact factors" are one method for determining the "value" of a journal and such factors are considered by many institutions for purposes of conferring promotion, tenure, and grant monies to those who publish in "high impact" journals. The term "impact factor" was coined by Dr. Eugene Garfield and applies only to those journals indexed by Thomson Scientific in the Web of Science $^{\circledR}$ (described in Section 3.2.2.1). The impact factor is determined by a simple mathematical formula that divides the number of published articles in a 2-year period of a journal title, by the number of citations to those same articles in a different 2-year period (Garfield 1994). The impact factor is highly controversial, widely misunderstood, and frequently irrelevant in fisheries science for two reasons. First, the Web of Science ${ }^{\circledast}$ does not index many relevant fisheries publications that fall outside of the mainstream. Second, many 
fisheries scientists publish outside of fisheries journals, so the relative impact of the 40 titles in the fisheries cluster does not reflect the importance of an article in Conservation Biology, for example. The Web of Science ${ }^{\circledast}$ does not quickly add titles due to changing research interests; for example, Fisheries Oceanography, first published in 1992, was not indexed in the Web of Science ${ }^{\circledast}$ until the last issue of the 4th volume published in 1995, and Journal of Cetacean Research and Management first published in 1999 is still not covered in 2006. All the above suggests that the peer-reviewed journals have a definite place in documenting and communication fisheries science, but often too much emphasis is put on this sector of the information web (Lange 2002; Webster and Collins 2005).

\subsubsection{Professional and Trade Journals and Newsletters}

Essential to fisheries science are the publications produced by scientific societies and industry organizations. These often address applied research issues and results such as stock assessment, policy discussion, and trade information and trends. Such publications also take many forms including professional journals that may be peer-reviewed (Fisheries), trade journals (National Fisherman, World Fishing) or even popular magazines (Blue Planet, Oceanus). These publications are focused on specific aspects of a discipline, or may seek to bring varying viewpoints together around a particular technology or policy issue. Because much fisheries literature is "applied" rather than "experimental" in nature, these publications provide an important outlet for best practices, describing new gear or technologies, and stimulating debates by creating a forum for policy discussions.

\subsubsection{Grey Literature}

Another form of publication common to fisheries literature is the so called "grey literature." As the term suggests, this venue is not obvious and often not accessible to all, yet critical as it encompasses much that is not commercially published. Finding or consuming grey literature can be problematic because not enough attention is paid by authors producing it. A prime example is a technical report containing datasets and observations that are not distilled into a format suitable for publication in a several page article. Master's theses or doctoral dissertations may be considered grey literature, as are data sets or time series. Grey literature may be individual reports or comprise parts of long standing series (such as the many series published by FAO). It is often published by government entities, non-governmental organizations and international organizations. Distribution may be extremely limited, yet critical to those seeking to understanding a particular issue or searching for a specialized dataset. This limited distribution, coupled with lack of peer-review, means that grey literature is under-represented or excluded from many general abstracting and indexing services. Specialized databases (such as ASFA and Fish and Fisheries Worldwide), however, specialize in identifying such literature, which further extends 
the value and importance of the data to scholars and policy makers. Grey literature may also be assembled into aggregated databases such as the National Sea Grant Library (National Sea Grant Library 2006) or in collections at government agencies (Office of Scientific and Technical Information (U.S.) 2006) or organizational repositories (Food and Agriculture Organization of the U.N. 2006).

Even though distribution is uneven and publications may be difficult to locate, the grey literature in fisheries science provides a large reservoir of important information. Some classic studies were originally published in government series (Beverton and Holt 1957). Practical management guidelines often appear in this venue. Even the fodder for ongoing debates can first appear in the grey literature (Food and Agriculture Organization of the U.N. 1995; Pew Oceans Commission and Panetta 2003). For many fisheries scientists, this is their venue as their agencies and organizations expect reports and not finely tuned journal articles; or, their annual reports or technical handbooks are more appropriate means of communicating to their audience. Grey literature takes many forms, with varying styles and differing purposes. As a venue, though, it is important to recognize and use it.

\subsubsection{Copyright}

Copyright is an important but subtle and often confusing aspect of scientific publishing. It used to be a peripheral concern when making decisions about publishing venue. Now, copyright can be a deciding factor in whether an article is accessible to all readers and usable by the authors. It is worthwhile to have a working knowledge of copyright so authors can make thoughtful decisions.

Copyright laws differ from country to country, but all seek to protect the intellectual property of an author. The World Intellectual Property Organization (WIPO) and treaties such as the Berne Convention (signed by 162 countries since its inception in 1886) work towards collaborative and shared recognition and enforcement of member nations' copyright laws. At the most basic level, copyright confers to the copyright owner specific privileges:

- The right to reproduce the work;

- The right to prepare or authorize derivative works based upon the copyrighted work;

- The right to distribute copies and collect royalties;

- The right to display or perform copyrighted works.

Copyright typically resides with the creator of a work. One significant exception is that the work of US Federal Government employees is not copyrighted and is in the "public domain" where it is freely usable by anyone anywhere in the world. This is also true for many state employees, although the law varies from state to state and institution to institution. 
A perplexing trend has taken place in scholarly scientific publishing over the years. Publishers usually require authors to sign over their copyrights to the publisher in order to have the work published in a scientific journal. Publishers claim that this right is necessary for them to protect and responsibly manage that piece of intellectual property for the legal term of the copyright. In the US, copyright currently lasts for the life of the author plus 70 years, which seems an nordinately long term for a scientific work to need protection or to be managed. Further, while copyright transfer is common practice in scientific publishing, it is not common with many other types of publishing (such as fiction and legal publishing).

Because copyright assignment gives exclusive rights to the copyright holder, authors (aka creators of the work) may be prohibited from using their own work in other format or forum - such as classroom teaching, distributed learning, for inclusion in other works, or posting on a personal web site. Alternative copyright models are emerging and understanding of constraints of current practice is growing. For example, in the United Kingdom authors can assign their copyright to a publisher, while at the same time retaining the moral rights (as opposed to economic rights) to their intellectual property. Moral rights involve "the right to claim authorship of a work, and the right to oppose changes to it that could harm the creator's reputation" (World Intellectual Property Organization 2006). More authors are refusing to sign away their copyright, and instead choosing to give non-exclusive rights to publishers for first publication of their work, while retaining for themselves other rights (such as classroom and instructional uses). There are also new copyright models such as the Science Commons and Creative Commons models that enable authors to retain their copyright while assigning various levels of uses of their work (Creative Commons 1999; Creative Commons 2005) (Fig. 2.4).

SHERPA/RoMEO Service provides information on the copyright policies of various publishers (SHERPA and University of Nottingham 2006). It grew out of the 2002/03 RoMEO Project (Rights MEtadata for Open Archiving) of the Joint Information System Committee of the UK at the University of Loughborough (Joint Information Systems Committee 2006). The project correctly identified a need to document publisher policies as interest in self-archiving grows. Most publishers allow authors to post their work online; however many have restrictions to how this is done and what can be posted (e.g. pre-print, post-print, article pdf). This service assists authors who want to better understand their rights before or after publishing as well as others who may want to use a copyrighted article (Fig. 2.5).

A wealth of copyright resources exists for authors. At times, there is too much information so we tend to ignore it and hence are faced with consequences that can be problematic. As an author, you should check your organization's guidelines (if they exist) so you know what your rights may be. If none exist, use other available resources such as a university's or a government's copyright site (Table 2.1). Also, read the publisher's copyright agreement and amend it to address your need to archive and access your work. Ignorance is not bliss when it comes to copyright in the digital age. 


\section{ADDENDUM TO PUBLICATION AGREEMENT}

1. THIS ADDENDUM hereby modifies and supplements the attached Publication Agreement concerning the following Article:

$\overline{\text { (manuscript title) }} \overline{\text { (journal name) }}$

2. The parties to the Publication Agreement as modified and supplemented by this Addendum are:

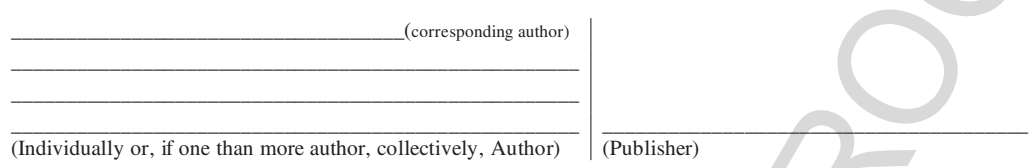

3. This Addendum and the Publication Agreement, taken together, allocate all rights under copyright with respect to all versions of the Article. The parties agree that wherever there is any conflict between this Addendum and the Publication Agreement, the provisions of this Addendum are paramount and the Publication Agreement shall be construed accordingly.

4. Author's Retention of Rights. Notwithstanding any terms in the Publication Agreement to the contrary, AUTHOR and PUBLISHER agree that in addition to any rights under copyright retained by Author in the Publication Agreement, Author retains: (i) the rights to reproduce, to distribute, to publicly perform, and to publicly display the Article in any medium for noncommercial purposes; (ii) the right to prepare derivative works from the Article; and (iii) the right to authorize others to make any non-commercial use of the Article so long as Author receives credit as author and the journal in which the Article has been published is cited as the source of first publication of the Article. For example, Author may make and distribute copies in the course of teaching and research and may post the Article on personal or institutional Web sites and in other open-access digital repositories.

5. Publisher's Additional Commitments. Publisher agrees to provide to Author within 14 days of first publication and at no charge an electronic copy of the published Article in a format, such as the Portable Document Format (.pdf), that preserves final page layout, formatting, and content. No technical restriction, such as security settings, will be imposed to prevent copying or printing of the document.

6. Acknowledgment of Prior License Grants. In addition, where applicable and without limiting the retention of rights above, Publisher acknowledges that Author's assignment of copyright or Author's grant of exclusive rights in the Publication Agreement is subject to Author's prior grant of a non-exclusive copyright license to Author's employing institution and/or to a funding entity that financially supported the research reflected in the Article as part of an agreement between Author or Author's employing institution and such funding entity, such as an agency of the United States government.

7. For record keeping purposes, Author requests that Publisher sign a copy of this Addendum and return it to Author. However, if Publisher publishes the Article in the journal or in any other form without signing a copy of this Addendum, such publication manifests Publisher's assent to the terms of this Addendum.

AUTHOR PUBLISHER

(corresponding author on behalf of all authors)

Neither Creative Commons nor Science Commons are parties to this agreement or provide legal advice. Please visit www.sciencecommons.org for more information and specific disclaimers.
SPARC (the Scholarly Publishing and Academic Resources Coalition) and the Association of Research Libraries (ARL) are not parties to this Addendum or to the Publication Agreement. SPARC and ARL make no warranty whatsoever in connection with the Article. SPARC and ARL will not be liable to Author or Publisher on any legal theory for any damages whatsoever, including without limitation any general, special,
incidental or consequential damages arising in connection with this Addendum or the Publication Agreement.

SPARC and ARL make no warranties regarding the information provided in this Addendum and disclaims liability for damages resulting from the use of this Addendum. This Addendum is provided on an "as-is" basis. No legal services are provided or intended to be provided in connection with this Addendum.

\section{c) commons}

www.sciencecommons.org

Fig. 2.4 An example of a copyright addendum from Science Commons 


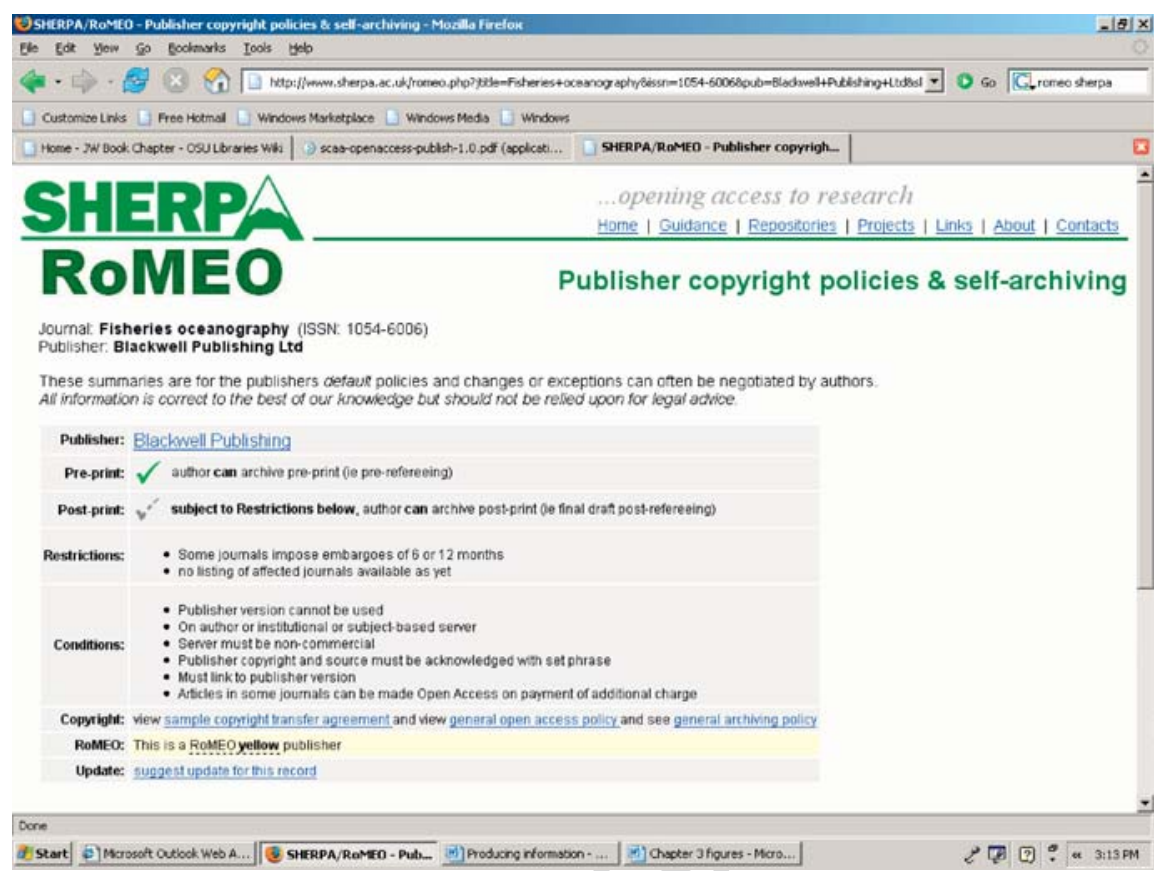

Fig. 2.5 Examples of a publisher profile from SHERPA/RoMEO

\subsubsection{Access}

Producing scientific information translates into providing access to it. This used to be straight forward; yet now, in the electronic environment, access issues present another set of decisions for authors. Scholarly communication as we now know it "began" in the 17 th century when reports of scientific discovery or

Table 2.1 Copyright resources

\begin{tabular}{|c|c|c|}
\hline Title & Web address & Description \\
\hline $\begin{array}{l}\text { Author's rights } \\
\text { (SPARC) }\end{array}$ & $\begin{array}{l}\text { http://www.arl.org/sparc/author/ } \\
\text { addendum.html }\end{array}$ & $\begin{array}{l}\text { Explains your rights as } \\
\text { an authors and } \\
\text { includes copyright } \\
\text { addendum }\end{array}$ \\
\hline $\begin{array}{l}\text { Scholar's Rights Project } \\
\text { (Science Commons) }\end{array}$ & $\begin{array}{l}\text { http://sciencecommons.org/ } \\
\text { literature/scholars_copyright }\end{array}$ & $\begin{array}{l}\text { Another example of a } \\
\text { copyright addendum }\end{array}$ \\
\hline $\begin{array}{l}\text { Copyright } \\
\text { Management Center } \\
\text { (Indiana University) }\end{array}$ & http://www.copyright.iupui.edu/ & $\begin{array}{l}\text { Explains U.S. copyright, } \\
\text { the concept of Fair } \\
\text { Use, and other } \\
\text { concepts }\end{array}$ \\
\hline $\begin{array}{l}\text { Copyright (World } \\
\text { Intellectual Property } \\
\text { Organization) }\end{array}$ & http://www.wipo.int/copyright/en/ & $\begin{array}{l}\text { A discussion of } \\
\text { copyright from an } \\
\text { international } \\
\text { perspective }\end{array}$ \\
\hline
\end{tabular}


observation were presented to scholars by reading them before the assembled members of scientific societies. The resulting papers were printed in compilations, the first being the Philosophical Transactions of the Royal Society (London) in 1665, and thus "the scientific journal" was born (Vickery 2000). For centuries printed journals were the norm, with the number of journal titles growing as new disciplines and sub-specialties of science developed. Scholarly societies and organization along with commercial ventures were all publishers serving different audiences and roles. The societies tended towards printing papers that had been presented and vetted within their meetings with others sought publishing as a means to broaden communication among scientists rather than within organizations (Henderson 2002; Vickery 2000).

As scholarly communication grew, its audience expanded and diversified, and the cost of producing, delivering and archiving scientific information increased as well (Prosser 2005). Today, we expect producers of scientific journals to offer multiple modes of access (print and electronic), more content (e.g. pages) and archives of all. Electronic full text access to current and old items should be within one or two clicks of a search. Our broader audiences also want ready access to the information fisheries scientists produce. They want it in a digestible format that is easily accessed. They do not subscribe to the scientific journals, so electronic delivery makes sense.

Thanks to the widespread adoption of personal computers, standardized software and stable file formats, nearly all scientific publications are "born digital." Digital content can easily be converted into appropriate styles or formats, and delivered on the Web through the sophisticated web sites of major scientific publishers to workable government and academic sites as well as a myriad of other web presences. Digital files, distributed across the Internet, have drastically altered the reach and potential markets for scientific literature. In fact, the print journal we have known since the 1600s is considered by many to be nearing extinction or at best to being an archival format.

Online journals developed from the expansion of "born digital" information and the global spread of Internet technologies. These are available in multiple forms and collections with associated differences in how potential readers must access the content. The two primary types are the traditional journals that are now available in electronic form (e.g. Reviews in Fisheries Science) and the open access journals (e.g. Scientia Marina). The electronic equivalent of print journals must still be purchased for the most part. They may be distributed on an individual basis, gathered into collections by the publisher, or aggregated into bundles of journals from a multiple publishers. A particular journal title might even be available via any or all of these mechanisms, and such compilations may be "full-text" cover-to-cover or just select portions of journals (for example research articles but not news or letters to the editor). Multiple mechanisms allow users to pick the one that fits their budget; however, it also means that libraries may have to duplicate purchases to capture all the content. As an author, you want to explore how your article is marketed as that affects how people access it. If too expensive or if included in an aggregated package that 
many find too confusing to purchase, your work may be essentially "lost" to parts of the audience.

New initiatives promote "open access" to scientific literature, whereby articles are either published in an "open access" journal or posted to an electronic repository. One of the clearest definitions of "open access" is found in the Budapest Open Access Initiative:

\begin{abstract}
By 'open access' to this literature, we mean its free availability on the public internet, permitting any users to read, download, copy, distribute, print, search, or link to the full texts of these articles, crawl them for indexing, pass them as data to software, or use them for any other lawful purpose, without financial, legal, or technical barriers other than those inseparable from gaining access to the internet itself. The only constraint on reproduction and distribution, and the only role for copyright in this domain, should be to give authors control over the integrity of their work and the right to be properly acknowledged and cited
\end{abstract}

Chan et al. (2002)

This concept and the initiatives it has spawned change the landscape of scholarly communication and access. Authors can retain control over their copyright and hence exercise more control of the access to their work. Such radical change does not come easily, quickly or smoothly. Yet, change does seem to be happening. Driven by initiatives such as the Open Archives Initiative and the Berlin Declaration, efforts vary from country-to-country (Van de Sompel and Lagoze 2000; Gruss and German Research Organizations 2003). The Open Access movement suggests new responsibilities for authors including making sure that they retain their rights to give their work to the public and that it is stored in a stable manner. New requirements by funders and institutions are one impetus for the growth of open access. For example, in 2005 the US National Institute of Health started requesting all grantees to deposit their findings in PubMedCentral. However, compliance is spotty and slow. Others have also found authors slow to put their material in publicly accessible sites; but persistence and mandates work over time (Sale 2006). It is important to note that while open or public access is a fairly recent phenomenon, studies show that the "impact" and citedness of such articles is as high as or better than articles published in traditional journals (Kousha and Thelwall 2006; Antelman 2004; Harnad and Brody 2004). Considering the alternatives to commercial journals and traditional publishing outlets is valid when producing information; "open access" journals and e-repositories may provide better access to your work for your intended audience.

Beyond the traditional scientific journal and the growing open access movement, we are learning how to share our research in other ways. No longer dependent on the mail and correspondence, we share research findings, collaborate in real time across tremendous distances, and participate in "live" debates with just a few keystrokes on the Internet. Technological advances and relatively inexpensive gadgets make it possible to talk (using Voice Over Internet Protocol or VOIP), participate in video conferences, and hold interactive distributed online seminars called "webinars". Blogs (web logs or online diaries), wikis, and other 
collaborative authoring tools are also drastically changing how scientists do business. Such low-cost tools make it possible for scientists, students, and policy-makers anywhere on the globe (or even in space) to quickly communicate with others and quickly disseminate information. Despite reports by Christopher Columbus in 1492, it appears that the world really is flat.

\subsubsection{Archiving}

Access and archiving are linked in the electronic environment; you cannot access an electronic document unless it has been stored in some logical, stable manner. File drawers and library shelves historically held the archives of the scientific debate but the digital millennium changes this norm. Now, you are more likely to post a pdf of your article to your web site than to order a box of reprints from the publisher. Or, you rely on the publisher to maintain an electronic copy on its server. Both options are tenable, but may have legal implications or monetary limitations. You can usually satisfy the former if you reserved the right to post a copy of the pdf to a publicly accessible site when signing your copyright statement. The later can be more complex.

With access licenses comes the vulnerability that access to information ends when one stops paying "the rent." Usually, the library pays "the rent" through contractual agreements with the publishers for access. Publishers make their digital archives available, some at a high cost to libraries and institutions, and others more altruistically, making them publicly available at no or low cost. An example of a commercial model is ScienceDirect, Elsevier's online journal collection; an institution can subscribe to some or all of the content of Elsevier's vast suite of scientific journals depending on the strength of its budget and the need of its researchers. PubMed Central sponsored by the U.S. National Institute of Health is a different archiving model; here all articles are freely accessible to all. As publishing mergers continue, archives change hands and access costs and rights can change with new owners. Unstable budgets can interrupt service and libraries lose access to previously licensed archives. And, authors lose access to their work. Identifying how your work will be archived is yet another step in the production cycle. Again, there are choices and consequences of those choices.

In an attempt to archive and secure ongoing access to their contribution to the scholarly process, many entities are creating institutional repositories (IR) as a digital preservation space (University of Houston Libraries, Institutional Repository Task Force and Bailey 2006). Institutional repositories provide a service to collect, archive and provide access to the information produced by members of a defined community such as a university or a discipline (Lynch 2003). They create a virtual and intellectual environment for the community's digital output. They are an attempt to address the challenges of digital archiving, the expectations of the campus and research community for better access to 
information, and the inadequacies of the current cumbersome model for scholarly communication. Various organizational models, software and hardware are emerging as more universities and agencies implement IRs (Crow 2004).

\subsubsection{Information Produced}

As fisheries scientists, we want to share our work with colleagues, policy makers and the public. Computers make it easier to produce work by streamlining our writing and editing. With the Web, we can now also easily publish our work making it accessible to all. However, producing quality information still involves multiple steps that affect its credibility and use. Scholarly communication is changing, and you need to recognize where and how you can change your actions to improve the information landscape. Consider your audience and its information consumption behavior. Also, consider your future audience. Such consideration will help you decide where you publish as it will suggest how your work will be identified and accessed by readers today and tomorrow.

\subsection{The Future of Fisheries Information}

While the life cycle of fisheries information remains constant through consumption and production, its environment is changing. Much of the change is driven by the integration of technology into how we "do" science. The change is inevitable; however, as fisheries scientists, we can shape the environment by making the communication of science better - more timely and accessible while maintaining our credibility and honesty. This takes effort and a willingness to modify some of our ways of consuming and producing information. Engagement in the discussion about scholarly communication is imperative, followed by action. Open and efficient access to fisheries information requires shifts in how we finance production of information. This encompasses the debate over journal pricing, the open access principles and the future of the scientific journal. Ease and stability of access requires us to work with those who design and maintain search systems, databases, and archives so the systems respond to our needs.

\subsubsection{Changing Economics of Fisheries Information}

The old system of scholarly publication cannot be sustained given changing user expectations and economics. Pricing continues to escalate with great variability among publishers. For example, in 2004 study, median overall journal prices vary from $£ 124$ (Cambridge University Press) to $£ 781$ (Elsevier) (White and Creaser 2004). Price increases from 2000 to 2004 ranged from 27\% (Cambridge University Press) to 94\% (Sage), well above any inflation factor 
(White and Creaser 2004). Yet we continue to struggle to implement a new publishing model that improves access and archiving for all.

Commercial publishers expect profit margins and must often pay dividends to their stockholders. Professional societies generate income from subscriptions, and use the income to provide benefits to members. All publishers need to cover costs. At issue is how to do that in an equitable manner as well as one that promotes open and efficient scholarly communication (Edwards and Shulenburger 2003). Authors provide and consume the product. Yet, the costs are usually born by their institutions.

Print subscriptions are sold to individuals (or perhaps are included as a benefit of membership in a particular society) for their personal use. These same journals are sold to libraries at a higher cost because they are accessible to many potential readers. Publishers have discovered that scientific articles are themselves discrete information commodities that can be sold in a collection, bundled into packages of often unrelated journals, or one-by-one. Unlike print journals, publishers have many different market models for pricing online subscriptions, for example, charging based on the number of "FTE" (full time equivalents) of faculty, staff, and students; or by the total amount of grant dollars received; or the number of advanced degrees conferred in a particular subject by an institution. Publishers may offer a subscription at one price to a small marine laboratory and the same publication at a completely different price to a neighboring university. Standard pricing appears to have disappeared as "deals" and "negotiations" have become the norm (Frazier 2001). Access to the article-level is also possible via alternative means and costs, including by subscription to an entire journal or on a pay-per-view basis.

In addition to the highly variable subscription prices of scientific journals, authors may face additional costs. Author fees (typically called "page charges" or "color charges") are commonly found in society journals. The charges offset the expense of printing and allow societies to sell subscriptions at a "subsidized" or lower cost. Author charges may or may not be payable with grant funds, or an institution may pay on behalf of its authors. Emerging models that allow "open access" may also come at a cost borne by the author or her/his institution.

Simultaneously, open access publications such as the Public Library of Science, have been subsidized by grants and are provided to readers free. Some open access publications offer institutional subscriptions that afford authors at the institution with reduced page charge fees. Even so, the market continues to evolve and access may be "embargoed" whereby current articles are closed, but older articles are "open access" or there may be a mix of access types within current issues (for example Limnology and Oceanography where an article can be "unlocked" or made open access by payment of an additional "page charge").

Theoretically, online publication should reduce costs because there are fewer steps and "consumables" (paper and ink) used in the production process as well as reduced costs formerly associated with postage, shipping and handling. However, in many cases the move to electronic delivery and access has 
significantly increased the cost to acquire scientific literature. Publishers insist that online publishing has raised their costs due to the need to upgrade and maintain servers and authentication mechanisms for online subscribers. So, while digital publishing increases the timeliness of access, it also compounds the ways users can access the material and the ways publishers can sell the product (Quandt 2003). It complicates things for all, just when we believe that scholarly communication should be easier, faster and cheaper.

Scientific publishing is rapidly evolving and unsettled, driven by technology and the growth of Internet-based services. For centuries, libraries preserved the scientific record by purchasing journal subscriptions, binding loose issues into complete volumes, cataloguing and preserving them and making collection available to current and future generations of students and scholars. But by the late 20th century, the information moved off the printed page, and access and archiving are no longer assumed with the purchase of a subscription to a journal or electronic book.

One approach to the problem is more funding for institutional purchases of electronic information; that is not going to happen at most institutions and still leaves those fisheries scientists unaffiliated with a strong library or research institution unable to get full access to the information needed. A more realistic approach requires government funded research to be published in a publicly accessible venue (Edwards and Shulenburger 2003). An immediate step authors can take is to deposit their publications in a stable electronic repository that is openly accessible and searchable (OhioLINK Governing Board 2006). Change in the publishing landscape is happening rapidly; changing our behavior as consumers and producers is slower, and we need to remedy that to maintain quality fisheries science.

\subsubsection{Ensuring Access to and Preservation of Fisheries Information}

Ease and stability of access to information relate to changes in the publishing landscape, yet have unique issues as well. Ease of access implies improved search interfaces and algorithms as well as more connectivity among sources of information. This challenge seems overwhelming, but realistically can be addressed at various scales and by a range of users. Locally, scientists can work with their librarians and computer scientists to make sure information created and stored locally is easy to search, find and use. A concrete example is to examine how you store your article reprints; are they in a secure and searchable place, or merely tucked on your own computer? Another example is considering how you construct and host a web site for your research project; is the metadata up to standards so it is indexed by web search engines or is the coding something you had not considered? Within professional societies, you can advocate for simple and intuitive interfaces to your organization's information and publications. Scientists should be willing to participate in studies on the 
usability of search systems, patterns of searching behavior and use of information. The more input on how search systems are used by those who really use them, the better the systems will eventually become.

Stability of access dictates if future fisheries scientists will be able find and use the information created today. With the evolution of publishing from print-only to print plus online models, there has been a cultural shift from "ownership" (whereby each library or individual purchases a subscription to the journal) toward an "access model" whereby libraries and publishers enter into contractual and license agreements that define the terms of access to and use of online content (Quandt 2003). Under this new model, instead of owning journals, content is "leased" and made accessible under specific terms for a specific period of time. Under the terms of contracts and licenses, when libraries cancel a subscription, they may lose access to all content they have leased in the past, thus ending up with nothing to show for their investment over time. The stable print archive the library used to represent has disappeared.

So, now we debate how to preserve scholarly information that we may or may not own, and do not really understand its technical life expectancy. CDRoms, once thought to be a good preservation medium, have been shown to fail much earlier than anticipated. Publishers have rushed to digitize past volumes of scientific journals, converting millions of print pages into bits and bytes stored on computers. In fact, that first scientific journal has been digitized as part of the JSTOR initiative so that all articles from 1665 are searchable, retrievable, and printable via any Internet connected computer if the searcher is accessing the resource through an institution with a subscription to this archive (JSTOR 2000-2006). Even when digitized, where is that article stored, in what format, and will we will be able to refresh it as software and hardware changes?

Fisheries scientists are not going to solve the digital preservation quandary. However, awareness of the fragility of digital information may make all of us more diligent with our decisions about storing our publications and data. Simple steps are critical, such as using standard formats for digital documents and adding basic metadata to datasets. More complex ones take greater effort and often specific expertise. These include building robust data repositories and experimenting with new ways of storing and accessing files. The keys to change here are involvement and collaboration. Waiting for the publishers to improve search interfaces and provide permanent archives may be waiting for an outcome that is untenable.

\subsubsection{Checklist for Consumers and Producers}

In the end, the cycle of science continues. The information that feeds new ideas and questions continues to be produced and consumed. Maintaining the vigor of fisheries science in the changing environment requires attention by all who are part of the information cycle. 
When consuming information:

- Consider your question before feasting on the information.

- Select the right tool and search strategy for your need.

- Try multiple tools and strategies. Do not assume that nothing exists on the topic.

- Remember that not everything is found by Google ${ }^{\mathrm{TM}}$. Science happened before computers were invented.

- Evaluate your sources. Everything you find is not true, accurate or timely.

- Keep track of the sources you find so you can use them accurately and ethically.

- Ask for help from an expert - a librarian or a colleague

When producing information:

- Think about your audience when writing.

- Consider the practices of publishers when selecting one.

- How do they establish prices?

- What is their policy for posting publicly accessible sites?

- Do they allow users in developing countries free access to their publications?

$\circ$ Do they charge you or your institution?

○ How will they store your work?

- Modify your copyright agreement to retain the rights your want.

- Deposit your publications in an open access repository.

- As a reviewer, consider the practices of the journal that asks for your time and expertise.

- As a member of a professional society, know your organization's policies and change the ones that inhibit the free flow of information.

- As a colleague and mentor, encourage others to join the discussion and change how we communicate.

- Check the SPARC site for current information on scholarly communication trends (Association of Research Libraries and Scholarly Publishing and Academic Resources Coalition 2006).

\section{References}

Antelman K (2004) Do open access articles have a greater research impact? College \& Research Libraries 65(5):372-82

ASFA Secretariat (2006) List of ASFA partners [Web Page]. Located at: ftp://ftp.fao.org/FI/ asfa/asfa_partner_list.pdf. Accessed 2006 Aug.

Association of Research Libraries, Scholarly Publishing and Academic Resources Coalition (2006) CreateChange: Change \& you [Web Page]. Located at: http://www.createchange. org/changeandyou.html. Accessed 2006 Sep 7

Avrahami TT, Yau L, Si L, Callan J (2006) The FedLemur project: federated search in the real world. Journal of the American Society for Information Science and Technology 57(3):347-58 
Chapter 2 October 3, 2008 Time: 21:19 Proof 1

Bauer K, Bakkalbasi N (2005). An examination of citation counts in a new scholarly communication environment. D-Lib Magazine 11(9):1-7

Beverton RJH, Holt SJ (1957). On the dynamics of exploited fish populations. London, UK: Her Majesty's Stationery Office; (Great Britain. Ministry of Agriculture, Fisheries and Food. Fishery Investigations: ser. 2, v. 19)

Chan L, Cuplinskas D, Eisen M, Friend F, Genova Y, Guédon J-C, Hagemann M, Harnad S, Johnson R, Kupryte R, La Manna M, Rév I, Segbert M, Souza S, Suber P, Velterop J (2002) Budapest Open Access Initiative [Web Page].

Located at: http://www.soros.org/openaccess/read.shtml. Accessed 2006 Sep 7

Creative Commons (1999) About Creative Commons [Web Page]. Located at: http:// creativecommons.org/. Accessed 2006 Sep 1

Creative Commons (2005) Scholar's copyright project [Web Page]. Located at: http:// sciencecommons.org/literature/scholars_copyright. Accessed 2006 Sep 1

Crow, R (2004) A guide to institutional repository software. Second Edition. Open Society Institute: New York

Edwards R, Shulenburger D (2003) The high cost of scholarly journals (and what to do about it). Change 35(6):10-9

Elsevier Ltd (2004) Scirus White Paper: how Scirus works. Amsterdam, Netherlands: Elsevier Ltd.

Food and Agriculture Organization of the U.N. (1958) Current Bibliography for Fisheries Science. Rome, Italy Vol. 1

Food and Agriculture Organization of the U.N. (1995) Code of conduct for responsible fisheries. Rome, Italy: FAO

Food and Agriculture Organization of the U.N. (2006) FAO Corporate Document Repository [Web Page]. Located at: http://www.fao.org/documents/. Accessed 2006 Sep 1

Frazier K (2001) The librarian's dilemma: contemplating the costs of the "Big Deal". D-Lib Magazine 7(3):10.1045/march2001-frazier

Garfield E (1994) The ISI impact factor. Current Contents: Agriculture, Biology, \& Environmental Sciences 25(25):3-7

Google (2005) About Google Scholar ${ }^{\mathrm{TM}}$ [Web Page]. Located at: http://scholar.google.com/ intl/en/scholar/about.html. Accessed 2006 Aug.

Gruss P, German Research Organizations (2003) Berlin Declaration on open access to knowledge in the sciences and the humanities [Web Page]. Located at: http://www.zim. mpg.de/openaccess-berlin/berlindeclaration.html. Accessed 2006 Sep 7.

Harnad S, Brody T (2004) Comparing the Impact of Open Access (OA) vs. Non-OA Articles in the same journals. D-Lib Magazine 10(6):doi:10.1045/june2004-harnad

Henderson. (2002) Diversity and the growth of serious/scholarly/scientific journals. [in] Abel RE, Newlin LW, ed. Scholarly publishing: Books, journal, publishers, and libraries in the Twentieth Century. US: John Wiley \& Sons, Inc. pp 133-62

Jacsó P (2005a) Google scholar: the pros and cons. Online Information Review 29(2):208-14

Jacsó P (2005b) Visualizing overlap and rank differences among web-wide search engines: some free tools and services. Online Information Review 29(5):554-60

Jacsó P (2006a) Savvy searching: deflated, inflated and phantom citation counts. Online Information Review 30(3):297-309

Jacsó P (2006b) Windows live academic. Péter's Digital Reference Shelf May 2006:3-6

Jacsó P (2006c) Scopus revisited. Péter's Digital Reference Shelf June 2006

Jansen BJ, Spink A, Saracevic, T (2000) Real life, real users, and real needs: a study and analysis of user queries on the web. Information Processing and Management 36(2000):207-27

Joint Information Systems Committee (2006). About JISC - Joint Information Systems Committee [Web Page]. Located at: http://www.jisc.ac.uk/. Accessed 2006 Sep 1

JSTOR (2000) About JSTOR [Web Page]. Located at: http://www.jstor.org/about/. Accessed 2006 Jan

Kousha K, Thelwall M (2006) Google Scholar citations and Google Web/URL citations: A multidiscipline exploratory analysis. [in] Proceedings International Workshop on Webometrics, 
Informetrics and Scientometrics \& Seventh COLLNET Meeting Nancy, France. Located at: http://eprints.rclis.org/archive/00006416/01/google.pdf Accessed 2006 Sep 1

Lackey RT (2006) Axioms of ecological policy. Fisheries 31(6):286-90

Lange LL (2002) The impact factor as a phantom: is there a self-fulfilling prophecy effect of impact? The Journal of Documentation 58(2):175-84

Lynch CA (2003) Institutional repositories: essential infrastructure for scholarship in the digital age. ARL Bimonthly Report 226

Mattison D (2005) Bibliographic research tools round-Up. Searcher 13(9):10704795

McDonald J, Van de Velde EF (2004) The lure of linking. Library Journal 129(6):32-4

National Sea Grant Library (2006) National Sea Grant Library [Web Page]. Located at: http://nsgd.gso.uri.edu/. Accessed 2006 Sep 1

Neuhaus C, Neuhaus E, Asher A, Wrede C (2006) The depth and breadth of Google Scholar: an empirical study. Portal: Libraries and the Academy 6(2):127-41

Office of Scientific and Technical Information (U.S.) (2006) GrayLIT Network: A science portal to technical papers [Web Page]. Located at: http://www.osti.gov/graylit/. Accessed 2006 Sep 1

OhioLINK Governing Board (2006) OhioLINK Library Community recommendations on retention of intellectual property rights for works produced by Ohio faculty and students [Web Page]. Located at: http://www.ohiolink.edu/journalcrisis/intellproprecsaug06.pdf. Accessed 2006 Sep 7

Page L, Brin S, Montwani R, Winograd T (1998) The PageRank citation ranking: bringing order to the Web. Technical Report, Stanford University Database Group

Pauly D, Stergiou KI (2005) Equivalence of results from two citation analyses: Thomson ISI's Citation Index and Google's Scholar service. Ethics in Science and Environmental Politics December 2005:33-5

Pew Oceans Commission, Panetta LE (2003) America's living oceans: charting a course for sea change: a report to the nation: recommendations for a new ocean policy. Arlington, VA: Pew Oceans Commission

Prosser DC (2005) Fulfilling the promise of scholarly communication - a comparison between old and new access models. [in]: Nielsen EK, Saur KG, Ceynowa K, eds. Die innovative Bibliothek: Elmar Mittler zum 65. Geburtstag. K G Saur. pp 95-106

Pruvost C, Knibbs C, Hawkes R (2003) About Scirus [Web Page]. Located at: http://www. scirus.com/srsapp/aboutus. Accessed 2006 Aug

Quandt RE (2003) Scholarly materials: Paper or digital? Library Trends 51(3):349-75

Ranganathan SR (1963) The five laws of library science. [Ed. 2, reprinted with minor amendments] Bombay, New York: Asia Publishing House

Roth DL (2005) The emergence of competitors to the Science Citation Index and the Web of Science. Current Science 89(9):1531-6

Sale A (2006) The acquisition of open access research articles. In Press. [Web Page]. Located at: http://eprints.comp.utas.edu.au:81/archive/00000375/ Accessed 2006 Sep 1

SHERPA, University of Nottingham. (2006) SHERPA/RoMEO Publisher copyright policies \& self-archiving [Web Page]. Located at: http://www.sherpa.ac.uk/romeo.php. Accessed 2006 Sep 1

Spink A, Cole C (2006) Human information behavior integrating diverse approaches and information use. Journal of the American Society for Information Science and Technology 57(1):25-35

University of Houston Libraries, Institutional Repository Task Force, Bailey CW (2006) Institutional repositories. Washington, DC: Association of Research Libraries, Office of Management Services

Van de Sompel H, Lagoze C (2000) The Santa Fe Convention of the Open Archives Initiative. D-Lib Magazine 6(2):DOI: 10.1045/february2000-vandesompel-oai

Vickery BC (2000) Scientific communication in history. Lanham, MD: Scarecrow Press

Webster JG (2003) How to create a bibliography. Journal of Extension 41(3) 
Chapter 2 October 3, 2008 Time: 21:19 Proof 1

2 The Consumption and Production of Fisheries Information

Webster JG, Collins J (2005) Fisheries information in developing countries: support to the implementation of the 1995 FAO Code of Conduct for Responsible Fisheries. Rome, Italy: Food and Agriculture Organization of the U.N.; (FAO Fisheries Circular No. 1006)

White RW, Jose JM, Ruthven I (2003) A task-oriented study on the influencing effects of query-biased summarisation in web searching. Information Processing and Management 39(2003):707-33

White S, Creaser C (2004) Scholarly journal prices: Selected trends and comparisons. Leicestershire, UK: Library and Information Statistics Unit, Loughborough University; (LISU Occasional Paper: 34)

World Intellectual Property Organization [2006]. Copyright FAQs: What rights does copyright provide? [Web Page]. Located at: http://www.wipo.int/copyright/en/faq/faqs.htm\#rights. Accessed 2006 Sep 1 


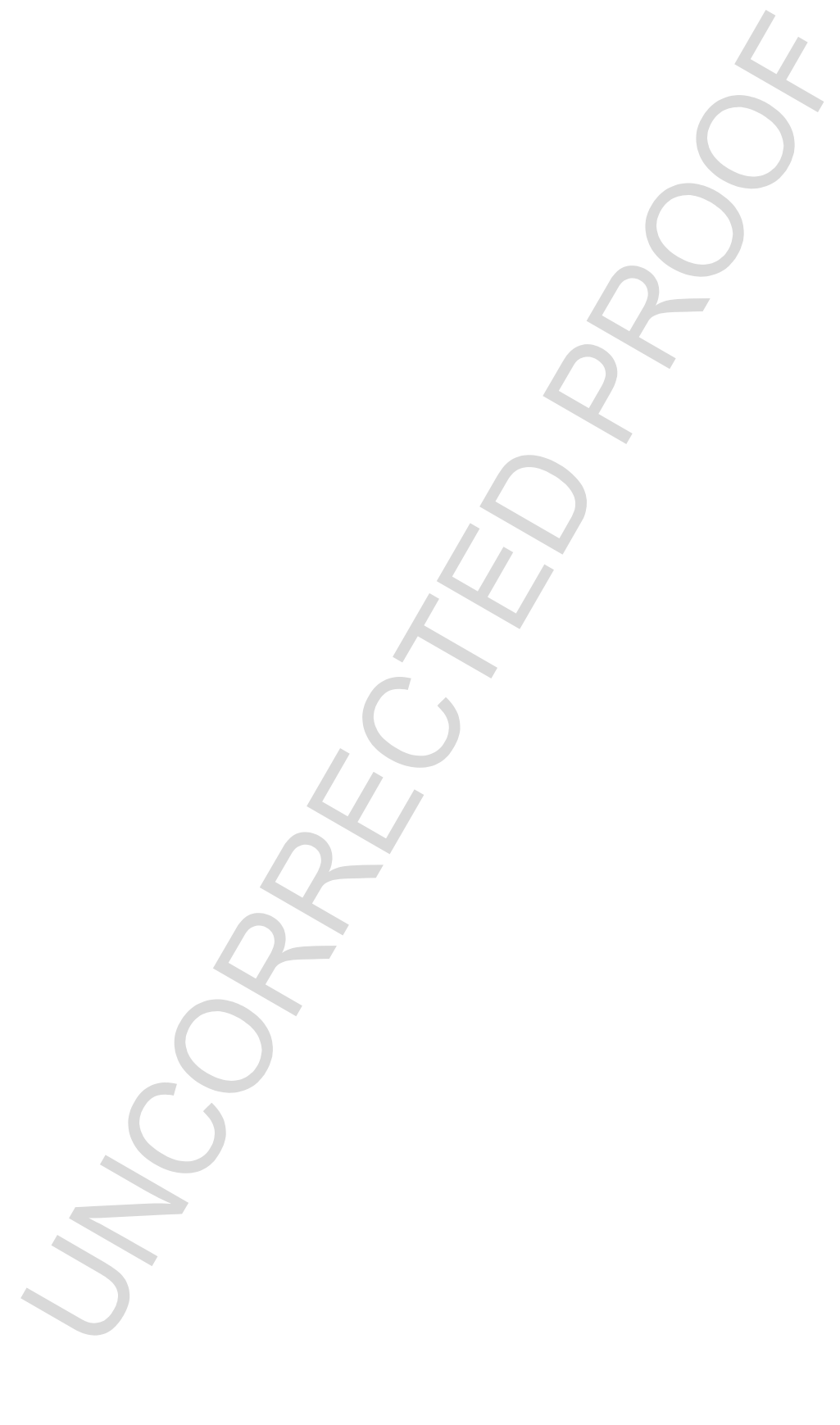




\section{Chapter 2}

\begin{tabular}{lccl}
\hline Query No. & Page No. & Line No. & \multicolumn{1}{c}{ Query } \\
\hline AQ1 & 51 & 39 & This Section is missing in Chapter 3. \\
AQ2 & 54 & 27 & We had inserted the Citations for Figures 2.4 \& 2.5. \\
AQ3 & 65 & 31 & Please provide the "Initial" for this Author. \\
AQ4 & 65 & 38 & Please provide "Full Details" for this Reference. \\
AQ5 & 65 & 39 & Please provide "Full Details" for this Reference. \\
AQ6 & 66 & 33 & Please update. \\
\hline
\end{tabular}

